\title{
Narrativa e Invenção: a Nação e a Aparência
}

\author{
RONALDO OLIVEIRA DE CASTRO
}

\section{CASTRO-SANTOS, Luiz Antônio. O Pensamento Social no Brasil. Campinas: Edicamp, 2003.}

O pensamento social no Brasil reúne artigos escritos por Luiz Antonio de Castro-Santos ao longo de 20 anos. Os artigos giram em torno de autores que teriam em comum a preocupação em pensar ou "inventar" o Brasil, produzir interpretações ou estratégias políticas que de algum modo contribuíssem para a superação de problemas nacionais.

São discutidos temas variados, como em que medida as interpretações de Gilberto Freyre sobre a ordem senhorial e escravocrata continuam válidas e o que podemos aprender com seus erros e acertos; o impacto da obra de Gilberto Freyre na historiografia norte-americana; um interessante confronto da Conquista da América, de Todorov, com Visão do paraíso, de Sérgio Buarque de Holanda.

No ensaio "Duas visões do paraíso (convite a Todorov para ler Sérgio Buarque de Holanda)", Castro-Santos discute como o livro do autor europeu trata justamente da descoberta que o eu faz do outro, revelando uma ausência de diálogo, que se daria de duas maneiras: primeiro, pela exclusão da América portuguesa do objeto de análise e, em seguida, pela exclusão da literatura sobre a experiência colonial portuguesa, acarretando uma perda na compreensão da conquista, uma vez que metade dessa experiência foi excluída até mesmo como elemento de comparação. Visão do paraíso seria ao mesmo tempo um livro mais modesto e abrangente, na medida em que se propõe a compreender os motivos edênicos na colonização portuguesa, e não na América, mas para isso recorre ao método comparativo, não perdendo de vista a América espanhola. Já a América de Todorov termina por se reduzir à experiência espanhola. A maior abrangência do texto de Sérgio e seu desconhecimento no 
exterior permitem que o autor desenvolva interessante discussão sobre o lugar do intelectual de países periféricos no sistema acadêmico internacional - lugar que seria um espaço de resistência e luta.

O exemplo de Sérgio demonstra que os trabalhos do intelectual de periferia dificilmente são lidos no centro; ainda assim, esse intelectual tem como dever não só manter-se atualizado com a produção local e internacional, como manter sua produção no nível desse interlocutor ausente, que é seu par dos países centrais.

Se de certa forma o ensaio aponta para a importância que Visão do paraíso poderia ter na discussão internacional sobre o tema da conquista, o texto seguinte ("A radicalidade de Os parceiros do Rio Bonito"), é dedicado a pensar o lugar que Parceiros do Rio Bonito, de Antonio Candido, ocupa nas ciências sociais brasileiras. Alguns aspectos dariam a esse livro uma projeção duradoura. Primeiro, um compromisso ético-político que aparece na denúncia do domínio oligárquico e das condições de vida no campo; em segundo lugar, a dimensão estética do texto; em terceiro, a contribuição metodológica marcada pela valorização do ato crítico e pela recusa do dogmatismo. A idéia do compromisso ético é extremamente interessante. Para Luiz Antônio de CastroSantos, Os parceiros revelariam a postura ética de Candido, encerrando uma lição de vida que recusaria a vaidade que esteriliza muitas vezes a produção, pois a vaidade impediria que a manifestação da subjetividade pudesse expressar também o coletivo, tornando-se mera expressão de idiossincrasias. A radicalidade do texto de Candido estaria no valor ético que une o autor e o seu texto, valor ético marcado pela sociabilidade e pela auto-estima que não impedem, mas incentivam a colaboração e o diálogo.

Na seqüência, "O pensamento sanitarista na Primeira República: uma ideologia de construção da nacionalidade" discute, através de Belisário Pena, como o pensamento sanitarista na República Velha estava associado a uma ideologia de construção nacional. A identificação dessa construção com a modernização também está presente em ensaio sobre Azevedo Sodré, parlamentar que na Primeira República também se envolveu nos debates sobre a modernização do país, através da reforma da educação e da saúde. Pena e Sodré aparecem como intelectuais que se colocam para além dos limites de pensamento que caracterizavam os interesses oligárquicos do Brasil do início do século XX. 
De certa forma, a mesma perspectiva aparece em "Índia, África, anos cinqüenta: relendo Ruy Miller Paiva”, texto dedicado a Ruy Miller Paiva, engenheiro agrônomo que se converteu numa espécie de economista rural preocupado em descobrir alternativas que pudessem resolver os mais graves problemas brasileiros. $\mathrm{O}$ artigo analisa os relatos de viagem de Miller Paiva à África e à Índia, discutindo como os interesses locais e nacionais do autor atuavam como ingrediente para sua abordagem do panorama internacional.

Outro texto da coletânea também se relaciona com a questão da modernização, e é uma crítica à idéia defendida por Paulo Eduardo Arantes, de que o positivismo teria sido, no Brasil da virada do século XIX para o XX, uma idéia fora do lugar, uma vez que nas matrizes européias a filosofia positiva teria exercido uma função modernizadora, enquanto no Brasil teria assumido aspectos conservadores. Castro-Santos, em "Meia palavra sobre a filosofia positiva no Brasil: diálogo com Paulo Eduardo Arantes", demonstra que o positivismo no país não pode ser pensado como uma corrente homogênea, pois havia uma corrente doutrinária que transformava a filosofia positivista numa retórica ornamental e descartável e um grupo positivista que poderia ser considerado pragmático e modernizador. Contudo, ambos seriam conservadores. Deste modo, o positivismo no Brasil, pelo menos em uma de suas tendências, tinha afinidades com os projetos de modernização conservadora. Porém, o conservadorismo do positivismo brasileiro não seria uma idéia fora do lugar, uma inversão do sentido que o movimento teria em seu local de origem, pela simples razão de que na matriz européia o positivismo também era uma filosofia conservadora, não podendo, no caso brasileiro, ser considerado uma idéia deslocada.

Se o livro de Castro-Santos trata de uma diversidade de temas, há um fio condutor que une os ensaios, que seria a idéia de construção da nação. Pode-se dizer que o livro trata de autores que partilham um certo estilo de pensamento que se caracterizaria pela tentativa de pensar, inventar ou construir o Brasil. Ainda assim, a diversidade de autores e problemas tratados dificulta a tarefa do resenhista, de modo que resolvi me deter sobre os artigos sobre Gilberto Freyre, que contêm algumas idéias recorrentes no livro, e porque é o autor de uma das mais importantes narrativas de construção da nação. Desta forma, esta resenha não esgota todos os temas do livro, mas tenta uma aproximação através da discussão de um autor que representa um paradigma quando se trata de discutir a invenção do Brasil. 
Um ponto que atravessa alguns textos de $O$ pensamento social no Brasil é a temática da vaidade. Aparece no artigo "A radicalidade de $O s$ parceiros do Rio Bonito", de Antonio Candido, como mencionado, mas é discutindo Gilberto Freyre que Castro-Santos constrói uma interessante sociologia da vaidade, um fator que comprometeria a produção intelectual de Freyre depois dos anos 40. O autor, tomado por um sentimento narcísico desmedido, teria nutrido uma admiração excessiva em relação às metrópoles, onde encontrara outros significativos para a avaliação de seus trabalhos. Com o sucesso internacional de seus primeiros trabalhos e o posterior retorno para o Recife, o autor teria organizado ao seu redor uma espécie de ambiente de culto. Freyre teria se convertido num intelectual de província, buscando pensarse a partir do exterior, medindo seu talento a partir dos intelectuais metropolitanos que tomou como seus pares, e demonstrando sinais de orgulho ferido com a queda de seu prestígio internacional e se isolando no que diz respeito ao debate intelectual no interior do Brasil. O cultivo da vaidade terminaria por tornar-se um culto ao elogio, tanto mais valorizado quanto mais comuns se tornavam as críticas no contexto local. Freyre teria se tornado, graças a sua "aventura cosmopolita", uma figura genial, mas que teria por fim sucumbido à vaidade.

Hanna Arendt é uma da referências teóricas da sociologia da vaidade que Castro-Santos realiza. A condição humana (Rio de Janeiro, Editora Forense Universitária, 2001) pode fornecer algumas reflexões para essa empresa. De acordo com a autora alemã, a aparência para nós é o real, o que significa que vivemos num mundo comum que adquire sua realidade através de uma linguagem que é pública. Isto é, aquilo que confere realidade a uma coisa não seria o fato de ela aparecer para todos nós da mesma forma, mas o fato de aparecer para todos, de constituir uma realidade para todos. Algo seria real para nós não porque todos concordamos sobre o que ele é, mas por todos estarmos interessados nele. Um objeto é real não porque todos dizemos a mesma coisa sobre ele, mas porque todos nós participamos deste mundo comum por meio de uma linguagem que é pública, isto é, porque falamos dele, ainda que discordemos sobre o que ele seja. Pode-se pensar a sociologia da vaidade, especialmente no caso da leitura que o autor faz de Freyre, a partir da idéia de que o real é constituído num mundo público ou comum.

Creio que, na interpretação de Castro-Santos, Gilberto Freyre, depois dos anos 40 - após ter produzido suas geniais interpretações do Brasil - não se contentava em estar num mundo comum, esfera de debates marcada pela 
condição humana da pluralidade. Era preciso o consenso, sua genialidade precisaria ser reconhecida por todos. Se a leitura que faço do texto de CastroSantos é correta, pode-se pensar a vaidade como um sentimento que leva a uma busca de constituição do self nesse espaço comum, reduzindo a diversidade de imagens, tentando impor uma única leitura de si. O que daria realidade ao self vaidoso não seria sua presença no debate público, mas o fato de ele se fazer presente de acordo com a sua imagem previamente traçada. Se a aparência para nós é o real, e o mundo público estaria marcado pela diversidade das interpretações, a vaidade exigiria que uma única aparência de si fosse exclusivamente identificada como a verdadeira, sem possibilidade de contestação. Essa imagem não seria uma construção pública, mas pessoal.

$\mathrm{Na}$ análise de Castro-Santos, a trajetória de Gilberto representaria a dissolução do orgulho de si mesmo (produtivo e justificável na época dos grandes textos dos anos 30) no culto à vaidade e ao elogio do Gilberto posterior a 1945. Se essa trajetória do orgulho à vaidade pode ser lida nos termos de uma recusa à construção pública da imagem de si, ou seja, de uma construção através do debate, então a análise que Castro-Santos realiza de Freyre talvez encontre um ponto de contato com a interpretação que Ricardo Benzaquen de Araújo faz de Casa-grande \& senzala em seu livro Guerra e paz-Casa-Grande \& senzala e a obra de Gilberto Freyre nos anos trinta (Rio de Janeiro, Editora 34, 1994). Não é minha intenção minimizar as diferenças entre as duas leituras. Araújo dedica-se justamente ao período em que, na interpretação de Castro-Santos, o orgulho ainda não teria se transformado em vaidade, o período das grandes obras de Freyre. O problema da vaidade, como tratada por CastroSantos, está para além do período discutido por Araújo. Contudo, na interpretação deste, Freyre, nos anos 30, envolveria sua obra numa atmosfera de autenticidade: a forma como constrói seu texto produz a impressão que este não é apenas uma interpretação do Brasil, mas corresponderia também a uma verdade pessoal. Como se a personalidade e o texto se interpenetrassem.

Para Ricardo Benzaquen de Araújo, a posição de Freyre poderia ser interpretada através da oposição entre sinceridade e autenticidade que Lionel Trilling apresenta em Sincerity and authenticity (Cambridge, Harvard University Press, 1971). Enquanto a sinceridade supõe um certo desprendimento de si, uma certa disposição universalizante que se efetiva num espaço público, a autenticidade marca justamente o desejo de expressão de uma interioridade que pode até mesmo se descomprometer com as normas da vida social. A 
sinceridade apontaria para o público, enquanto a autenticidade seria uma expressão do espaço interior, da intimidade.

Araújo se utiliza dessa noção de autenticidade como uma chave para compreender como Freyre transforma seu livro numa casa-grande em miniatura, isto é, numa metonímia da própria experiência em análise, na medida em que o ensaio histórico-sociológico se converte em memória íntima.

No entanto, a noção de autenticidade tem um ponto de contato com a idéia de vaidade: ambas se constroem a partir de um sujeito que busca exprimir uma imagem de si, sem passar pelas estratégias de um espaço público marcado por normas convencionais ou universais de expressão. A grande diferença é que a autenticidade de Freyre nos anos 30, se Ricardo Benzaquen de Araújo tem razão, resulta na produção de algumas das obras mais interessantes sobre a sociedade brasileira, enquanto que a vaidade, discutida por Castro-Santos, teria provocado um rebaixamento no nível de sua produção intelectual.

Não quero jogar um autor ou um conceito contra o outro, mas sugerir que o ponto de contato entre os dois pode ser significativo: autenticidade, orgulho e vaidade poderiam talvez ser relacionados. Talvez a vaidade pudesse ser pensada como a forma que a autenticidade de Freyre se expressa a partir de 1945, ou melhor, orgulho e vaidade em Freyre como duas formas de expressão da autenticidade, com rendimentos intelectuais distintos. Uma metáfora de Simmel utilizada por Castro-Santos pode colaborar para essa abordagem. Simmel associa o orgulho ao adorno autêntico e a vaidade ao adorno de bijuteria. Num trecho citado por Castro-Santos, o sociólogo alemão diz que "o adorno de bijuteria só vale pelo serviço que presta a seu portador. $\mathrm{O}$ valor do adorno autêntico vai mais além; tem raízes nas idéias de valor de todo o círculo social, e ramifica-se nelas" (p. 88). Em outras palavras, enquanto o valor autêntico ou sentimento de orgulho se constrói em consonância com os valores do público, a bijuteria corresponde a mero ornamento superficial. Castro-Santos apresenta a vaidade como uma forma de ser para os outros instável, pois o vaidoso se torna mais, e não menos dependente dos outros para a construção de sua autoimagem.

Nos termos apresentados, isso poderia ser explicado pela necessidade que o vaidoso teria de seduzir o público para sua auto-imagem previamente construída. O orgulho se relacionaria com uma atitude em que o ser para si aceita o diálogo com os outros. Pode-se lembrar do que Santos diz de Antonio 
Candido, do seu compromisso ético, de uma forma de construção de autoestima em meio a sociabilidade, estimulando o debate. Ou seja, uma autoimagem construída no interior de um espaço público, através do diálogo e não do culto ou da sedução. Assim, a autenticidade não pode ser equacionada ao orgulho, que facilmente pode ser aproximado da idéia de sinceridade, já que ambos são compatíveis com formas mais convencionais de expressão do que a autenticidade suportaria. Mas ainda que esta tenha se convertido em vaidade, Casa-grande \& senzala jamais poderia ser pensada como "bijuteria", pois se o texto transmite o interior do autor, revelando uma verdade pessoal, esta se converte em história íntima todo o brasileiro, na expressão do próprio Gilberto Freyre, o que significa dizer que, retomando Simmel, esta história tem raízes nas idéias de valor de todo um círculo social.

A discussão da vaidade não pode nos enganar. Para Luiz Antonio de Castro-Santos, Gilberto Freyre teria efetivamente contribuído para a compreensão da formação da sociedade brasileira, pelo menos em alguns dos seus aspectos. Contudo, teria produzido um quadro incompleto das categorias sociais envolvidas nesse processo de formação, já que "o escravo, enquanto categoria social fundamental para o surgimento daquela civilização, está ausente da análise freyriana" (p. 39). Essa idéia precisa ser qualificada, pois o escravo estaria presente no interior da casa-grande, aparecendo em função do senhor. Está ausente o escravo enquanto sujeito que desenvolve relações de sociabilidade próprias, mas, como disse Ricardo Benzaquen de Araújo, em livro já citado, o escravo estaria culturalmente presente no interior da casagrande.

Essa simultaneidade de presença e ausência adquire um novo matiz quando Castro-Santos discute a concepção de história social e da cultura de Freyre. Se esta é a primeira vista ampla, incorporando os grupos sociais dominados, termina por revelar-se estreita, pois se sustenta basicamente em termos culturais. Os grupos dominados da sociedade brasileira seriam apresentados nos textos de Freyre exclusivamente através de suas manifestações culturais. Desta forma de produzir história cultural resultaria uma folclorização do negro brasileiro. A crítica que Freyre recebe por se interessar somente pelas manifestações culturais dos dominados, por acentuar o sincretismo entre senhores e escravos, afastando-se da cultura e da sociabilidade negras consideradas em si mesmas, folclorizando-as, me parece que, apesar de sua verdade, deixa escapar algo. A ênfase na contribuição 
cultural negra coloca aqueles personagens, que nos planos econômico e político foram derrotados e dominados, como sujeitos produtores da sociedade brasileira. Os negros, em Freyre, não aparecem apenas como um instrumento do branco, mas como produtores da sociedade, como sujeitos. Isto não significa esposar a leitura generosa que José Honório Rodrigues faz de Freyre, ao sustentar que o sociólogo pernambucano seria, nas palavras de Castro-Santos, "o introdutor de uma nova perspectiva na historiografia brasileira, por ter conduzido o povo, enquanto categoria de análise, para o centro dos debates da história social do país" (p. 41). Os argumentos de Castro-Santos contra essa perspectiva são consistentes. É difícil sustentar que o povo esteja no centro da análise do processo de formação da sociedade brasileira, quando aparece apenas através da dimensão cultural. Contudo, com toda a nostalgia e fascínio que a vida patriarcal exercia sobre a imaginação de Gilberto Freyre, me parece lícito dizer que em Casa-grande \& Senzala o escravo adquire uma visibilidade que é única no pensamento social brasileiro. Os capítulos sobre a contribuição do negro para a vida sexual e de família do brasileiro revelam que o autor procurava demonstrar como a cultura brasileira teria se construído a partir da contribuição negra.

Se compararmos o modo como Freyre e Paulo Prado concebem a contribuição do negro para a formação da sociedade brasileira, o ponto pode ficar mais claro. Em Paulo Prado, a escravidão é uma instituição que deixa uma mácula em todas as instituições brasileiras. Se voltarmos para Freyre, podemos encontrar vários trechos de Casa-grande e senzala em que a escravidão é responsabilizada por uma série de problemas nacionais, incluindo o autoritarismo na política e a violência contra a mulher. Mas se nos dois autores a escravidão é acompanhada pela corrupção dos costumes, Freyre apresenta o escravo de origem africana como um civilizador. A escravidão em si mesma corrompe, mas essa corrupção é da instituição e não do negro.

Posso ser acusado de endossar a visão idílica da escravidão apresentada por Freyre, mas não é esta a intenção. Até porque o autor apresenta muitas passagens em que o idílio é interrompido e se revela a violência na relação entre senhores e escravos, inclusive nas relações sexuais, que, para o autor, seriam responsáveis por aproximar os dois grupos que a escravidão afastava. Apesar de vencidos, os escravos estavam aqui presentes, e contribuíram para moldar nossa sociedade. A imensa distância social entre senhores e escravos não impede a proximidade física, como revela o texto do próprio Freyre. 
Portanto, é plausível imaginar que a presença dos escravos domésticos tenha alterado a cultura dos senhores não apenas num sentido passivo, como na análise que Freyre faz do sadismo e do masoquismo, em que o moleque levapancadas não tem alternativa a não ser se sujeitar aos desejos do sinhozinho, a escrava é obrigada a ceder ao senhor, num processo de socialização do branco poderoso para a violência, mas também de modo mais ativo, através da língua, de sua cultura, do sincretismo.

Efetivamente permanece algo de fora, mas, ainda assim, há algo novo, há um personagem que deixa de ser concebido simplesmente como um instrumento passivo, mas como um sujeito que teria contribuído para a formação da sociedade. De qualquer modo, para Castro-Santos, Freyre apenas arranharia essa contribuição, porque não teria se dedicado a reconstruir as relações nas senzalas e nos mocambos.

Castro-Santos oferece uma leitura do mais forte legado de Gilberto Freyre. Se há uma série de ambigüidades nos seus textos, eles também ofereceriam uma análise consistente das tradições histórico-culturais que estiveram na base do processo de formação da sociedade brasileira, sem contudo negar importância "às forças materiais na conformação dos sistemas escravistas" (p. 81). Não há dúvida de que a rejeição de explicações monocausais é uma atitude que Castro-Santos partilha com Freyre. O final de um dos textos sobre Gilberto Freyre parece convidar o leitor para trilhar um caminho distinto daquele percorrido pelo autor, pois, durante todo o texto, Freyre aparece como o defensor da singularidade cultural, mas na conclusão não apenas somos lembrados que o sociólogo pernambucano não era insensível aos aspectos "estruturais" da sociedade escravocrata, como somos brindados com uma citação de Braudel, que defende que a história não pode ser concebida unilateralmente, pois seria essencialmente pluridimensional.

Talvez o texto de Castro-Santos pudesse ser lido como um convite para uma discussão do jogo entre o legado cultural ibérico e as estruturas próprias ao sistema escravocrata. Jogo que em Freyre não se fará sem algumas antinomias, pois encontraremos a idéia de que a escravidão gerou mais ou menos o mesmo tipo de patriarcalismo no sul dos Estados Unidos e no Brasil, como aparece no Prefácio à primeira edição, se contrapondo à tese de que o patriarcalismo brasileiro é uma herança ibérica, ou outros problemas semelhantes que podem representar uma abertura para essa pluridimensionalidade da história. Como disse Antonio Candido, em Formação da literatura brasileira, "é 
preciso sentir, por vezes, que um autor e uma obra podem ser e não ser alguma coisa, sendo duas coisas opostas simultaneamente, porque as obras vivas constituem uma tensão incessante entre os contrastes do espírito e da sensibilidade" (p. 23-24). (Formação da literatura brasileira, v. 1, Martins Fontes, São Paulo, 1ª ed., 1959).

\section{NOTAS}

${ }^{1}$ Professor assistente do Departamento de Ciências Sociais da UERJ; professor do Departamento de Sociologia e Política da Pontifícia Universidade Católica do Rio de Janeiro (PUC-RJ); mestre em Sociologia pelo Instituto Universitário de Pesquisas do Rio de Janeiro (IUPERJ). 